\title{
Tomato Below Ground-Above Ground Interactions: Trichoderma longibrachiatum Affects the Performance of Macrosiphum euphorbiae and Its Natural Antagonists
}

\author{
Donatella Battaglia, ${ }^{1}$ Simone Bossi, ${ }^{2}$ Pasquale Cascone, ${ }^{3}$ Maria Cristina Digilio, ${ }^{4}$ Juliana Duran Prieto, ${ }^{1}$ \\ Paolo Fanti, ${ }^{1}$ Emilio Guerrieri, ${ }^{3}$ Luigi lodice, ${ }^{3}$ Guido Lingua, ${ }^{5}$ Matteo Lorito, ${ }^{4}$ Massimo E. Maffei, ${ }^{3}$ \\ Nadia Massa, ${ }^{5}$ Michelina Ruocco, ${ }^{3}$ Raffaele Sasso, ${ }^{3}$ and Vincenzo Trotta ${ }^{1}$ \\ ${ }^{1}$ Dipartimento di Scienze, Università della Basilicata, Potenza, Italy; ${ }^{2}$ Unità di Fisiologia Vegetale, Dipartimento di Scienze \\ della Vita e Biologia dei Sistemi, Centro dell'Innovazione, Università di Torino, Via Quarello 15/A, Torino, Italy; ${ }^{3}$ Istituto per la \\ Protezione delle Piante Consiglio Nazionale delle Ricerche, Portici, Napoli, Italy; ${ }^{4}$ Dipartimento di Agraria, Università degli \\ Studi di Napoli "Federico II", Portici (NA), Italy; ${ }^{5}$ Dipartimento di Scienze e Innovazione Tecnologica, Università degli Studi \\ del Piemonte Orientale "A. Avogadro", Alessandria, Italy
}

Submitted 27 February 2013. Accepted 23 May 2013.

Below ground and above ground plant-insect-microorganism interactions are complex and regulate most of the developmental responses of important crop plants such as tomato. We investigated the influence of root colonization by a nonmycorrhizal plant-growth-promoting fungus on direct and indirect defenses of tomato plant against aphids. The multitrophic system included the plant Solanum lycopersicum ('San Marzano nano'), the root-associated biocontrol fungus Trichoderma longibrachiatum strain MK1, the aphid Macrosiphum euphorbiae (a tomato pest), the aphid parasitoid Aphidius ervi, and the aphid predator Macrolophus pygmaeus. Laboratory bioassays were performed to assess the effect of $T$. longibrachiatum MK1, interacting with the tomato plant, on quantity and quality of volatile organic compounds (VOC) released by tomato plant, aphid development and reproduction, parasitoid behavior, and predator behavior and development. When compared with the uncolonized controls, plants whose roots were colonized by $T$. longibrachiatum MK1 showed quantitative differences in the release of specific VOC, better aphid population growth indices, a higher attractiveness toward the aphid parasitoid and the aphid predator, and a quicker development of aphid predator. These findings support the development of novel strategies of integrated control of aphid pests. The species-specific or strain-specific characteristics of these below ground-above ground interactions remain to be assessed.

Terrestrial plants interact with an astonishing variety of micro- and macroorganisms. These interactions, both below ground and above ground, can be either beneficial or detrimental for their fitness. Only in recent years have the possible connections between these two "worlds" been studied in detail and some of the plant-mediated effects of these interactions assessed (Badri et al. 2012; Bezemer and Van Dam 2005;

Current address for R. Sasso: ENEA Centro Ricerche Casaccia UTAGRIECO, S. Maria di Galeria (RM), Italy.

Corresponding author: Emilio Guerrieri, E-mail: guerrieri@ipp.cnr.it

(C) 2013 The American Phytopathological Society
Guerrieri and Digilio 2008; Soler et al. 2013; Tikhonovich and Provorov 2011).

Plants represent the first level of a trophic chain including the consumers (e.g., insect, microbes, and mites) and their natural enemies or antagonists (including antagonistic insects, microbes, and mites), and this applies to both above ground and below ground (Heil 2008; Rasman et al. 2005). Co-evolution and human breeding shaped plant defenses against insects and pathogens in a process that may be exploited for sustainable management of plant protection. In the last two decades, there has been a growing interest for the multifaceted mechanisms of plant defenses against insects. In addition to physical (e.g., thorns) and chemical (i.e., anti-feedant and toxic compounds) barriers that directly affect the performance of the invading insect, plants exhibit indirect defenses based on the recruitment or enhancement of the activity of natural enemies, either predators (e.g., ladybirds) or parasitoids (e.g., Hymenoptera Ichneumonoidea and Chalcidoidea wasps) (Heil 2008). Indirect defense is accomplished by supplying food (e.g., extra floral nectars), by providing shelter (e.g., domatia), and, more often, through the production or release of volatile organic compounds (VOC) that are attractive toward entomophagous species. Only recently has it been shown that VOC release is also effective below ground for controlling nonarthropod species (Maffei et al. 2011; Rassman et al. 2005). Direct and indirect defense mechanisms can be further divided into induced, activated only following damage, and constitutive, which are always expressed and, thus, considered more expensive in terms of energetic cost for the plant (Heil 2008; Stamp 2003).

Recently, a number of studies investigated the possible effects of root colonization by microbes on plant defenses against above ground insects. For example, a mycorrhizal endosymbiosis in tomato plants significantly increased resistance toward aphids, activating both direct and indirect defense mechanisms (Guerrieri and Digilio 2008; Guerrieri et al. 2004). Similarly, it has been reported that root symbiotic microbes may reduce the negative effects of above ground insect chewers and sap-suckers (Pineda et al. 2010). However, the effect of Trichoderma spp., some of the most ubiquitous nonmycorrhizal plant-growthpromoting fungi (PGPF), on plant defense induction against insects have not been studied in detail so far (Pineda et al. 2010). 
Fungi belonging to the genus Trichoderma are distributed worldwide. They are known for their antagonistic activity against other microbes and their ability to colonize roots, establish chemical communication with the plant, and systemically alter the expression of many host genes. The success of this interaction may depend on the fungal strain-plant genotype combination (Tucci et al. 2011). The relevant changes caused by Trichoderma spp. in the plant physiology often result in an improved abiotic stress resistance, nutrient uptake, resistance to pathogens, and photosynthetic efficiency (Harman 2011; Harman et al. 2004; Hermosa et al. 2012; Lorito et al. 2010; Shoresh et al. 2010). Several recent papers reported the efficacy of Trichoderma spp. or their metabolites in terms of induction of systemic resistance against plant pathogens (Hanson and Howell 2004; Martinez et al. 2001; Vinale et al. 2012) but, to our knowledge, only a few papers focused on Trichoderma-plant-insect interaction have been published (Braun et al. 2012; Gange et al. 2012).

Among Trichoderma spp. used for biological control, Trichoderma longibrachiatum isolates have been described as strong producers of compounds known to be involved in antagonistic interactions, such as some lytic enzymes and secondary metabolites (Akpinar et al. 2009; Kim et al. 2010; Markov et al. 2006; Martinez et al. 2001). This species is distributed worldwide, commonly isolated from the root microenvironment of numerous plant species (Hermosa et al. 2004; Hoyos-Carvajal et al. 2009; Sariah et al. 2005; Zhang et al. 2005) and found able to control several plant pathogens (Freeman et al. 2004; Krauss and Soberanis 2001; Migheli et al. 1998; Sánchez et al. 2007; Yi and Chi 2011).

The aim of this study was to assess the effect of nonmycorrhizal PGPF T. longibrachiatum MK1 on above ground tomato insect communities as constituted by the tomato aphid Macrosiphum euphorbiae (Thomas) (Hemiptera: Aphididae) and its natural enemies: the predator Macrolophus pygmaeus (Rambur) (Hemiptera: Myridae) and the parasitoid Aphidius ervi Haliday (Hymenoptera: Braconidae). The hypothesis that

Table 1. Effect of Trichoderma longibrachiatum MK1 (mean values) on the development of tomato plant 'San Marzano nano'a

\begin{tabular}{lcc}
\hline Parameter & Control & Tl MK1 \\
\hline Stem length $(\mathrm{cm})$ & $15.2(1.9)$ & $19.2(2.4)^{* * *}$ \\
Shoot dry weight $(\mathrm{mg})$ & $145.2(18.3)$ & $187.8(23.3)^{* * *}$ \\
Root dry weight $(\mathrm{mg})$ & $203.3(25.6)$ & $267.5(33.9)^{* * *}$ \\
\hline
\end{tabular}

${ }^{a}$ Standard error is shown on parentheses. Asterisks indicate a significant difference $(P<0.001)$.

Table 2. Headspace volatile organic compounds collected from tomato plants ('San Marzano nano', 5 weeks old) uncolonized (control) and colonized by Trichoderma longibrachiatum MK1 (T1 MK1)

\begin{tabular}{lll}
\hline & \multicolumn{2}{c}{ Mean values $\left(\boldsymbol{\mu \mathbf { g ~ g } ^ { - \mathbf { 1 } } \text { fresh weight } ) ^ { \mathbf { a } }}\right.$} \\
\cline { 2 - 3 } Compound & Control & Tl MK1 \\
\hline (Z)-3-hexenol & $0.02(0.002)$ & $0.06(0.03)^{*}$ \\
$\alpha$-Pinene & $0.59(0.29)$ & $3.14(1.25)^{*}$ \\
$\delta$-2-Carene & $0.01(0.002)$ & $0.004(0.001)$ \\
$\alpha$-Phellandrene & $0.11(0.04)$ & $0.57(0.21)$ \\
$p$-Cimene & $0.12(0.05)$ & $0.23(0.08)$ \\
limonene & $3.79(1.88)$ & $0.73(0.16)$ \\
(Z)- $\beta$-ocimene & $0.01(0.01)$ & $0.05(0.02)$ \\
Methyl salicylate & $0.10(0.04)$ & $0.48(0.17)^{*}$ \\
Longifolene & $0.02(0.01)$ & $0.26(0.14)^{*}$ \\
$\beta$-Caryophyllene & $0.58(0.27)$ & $3.31(1.23)^{*}$ \\
(E)-jasmone & $0.01(0.003)$ & $0.01(0.002)$ \\
(Z)-jasmone & $0.15(0.09)$ & $0.38(0.16)$ \\
\hline
\end{tabular}

${ }^{a}$ Standard error is shown on parentheses. Asterisk indicates a significant difference $(t$ test, $P<0.05)$. the Trichoderma sp. affects the above ground plant-insect interactions was tested by using an integrated approach involving biological, behavioral, and chemical bioassays.

\section{RESULTS}

Root colonization by $T$. longibrachiatum MK1 promotes tomato development and production of VOC.

Plant development was generally promoted by $T$. longibrachiatum MK1 treatment as compared with controls. Shoot length and shoot and root dry weight increased by 20, 23, and $24 \%$, respectively, when compared with uncolonized controls (Table 1). The VOC composition obtained from the two treatments is reported in Table 2. Head-space analyses identified 12 compounds in the air-entrainment system of both control and T. longibrachiatum MK1-colonized plants. The release of five compounds (namely, cis-3-hexen-1-ol, $\alpha$-pinene, methyl salicylate, longifolene, and $\beta$-caryophyllene) was significantly stimulated by T. longibrachiatum MK1-colonization.

\section{Root colonization by $T$. longibrachiatum MK1 significantly improves development and reproduction of Macrosiphum euphorbiae on tomato.}

Aphid fertility (Ro) nearly doubled and doubling time (DT) nearly halved on tomato plant colonized by $T$. longibrachiatum MK1 as compared with uncolonized-controls (Table 3). This resulted in a significantly higher rate of population increase $\left(r_{\mathrm{m}}\right)$ on $T$. longibrachiatum MK1-colonized plants compared with controls $(t=144.79$, df 1998, $P<0.001)$. No significant difference (n.s.) was recorded in adult longevity $(t=0.399, \mathrm{df}$ 103 , n.s.), while the progeny $(t=3.160$, df $103, P=0.002)$ and the number of reproducing aphids $\left(\chi^{2}=3.94\right.$, df $\left.1, P<0.05\right)$ were positively influenced by the presence of the root-associated fungus (Table 3).

\section{Root colonization by $T$. longibrachiatum MK1 increases tomato attractiveness toward $A$. ervi.}

Root colonization by $T$. longibrachiatum MK1 resulted in a significantly higher attractiveness toward the aphid parasitoid A. ervi $(P<0.01, \mathrm{G}$ test for independence) (Fig. 1). T. longibrachiatum MK1-colonized plants were twice as attractive as control plant in terms of oriented flights. Conversely, the percentage of landings was not affected by root colonization (Fig. 1).

\section{Root colonization by $T$. longibrachiatum MK1 affects host plant selection and reproduction of aphid predator on tomato.}

Preliminary observations showed that Macrolophus pygmaeus preferred tomato plants infested by Macrosiphum euphorbiae when tested against uninfested plants $\left(\chi^{2}=5.062\right.$; $\mathrm{df}=1 ; P<0.05$ ) (Fig. 2). Root colonization by $T$. longibrachiatum MK1 significantly altered the behavioral response of

Table 3. Life parameters of Macrosiphum euphorbiae reared on tomato plants uncolonized (control) and colonized by Trichoderma longibrachiatum MK1 (Tl MK1)

\begin{tabular}{lcc}
\hline Parameter & Control & Tl MK1 \\
\hline $\mathrm{R}_{0}$ & 4.887 & 8.962 \\
$r_{\mathrm{m}}$ Bootstrap (per day) & $0.163 \pm 0.011$ & $0.228 \pm 0.008^{* * *}$ \\
Doubling time & 4.211 & 2.961 \\
Longevity (days) & $10.34 \pm 2.87$ & $10.12 \pm 2.90$ \\
Progeny & $4.85 \pm 0.76$ & $8,96 \pm 1.06^{* *}$ \\
Reproducing aphids & 30 & $39^{*}$ \\
$n$ & 53 & 52 \\
\hline
\end{tabular}

a Asterisks indicate a significant difference; $* * *$, and $* * *=P<0.05$, 0.01 , and 0.001 , respectively. 
M. pygmaeus. In choice experiments, in the complete absence of aphid infestation, plants colonized by $T$. longibrachiatum MK1 were significantly more attractive for Macrolophus pygmaeus females than uncolonized controls $\left(\chi^{2}=5.19\right.$; d.f. $=1$; $P<0.05$ ) (Fig. 3 ). These differences vanished when both controls and T. longibrachiatum MK1-colonized plants were infested by Macrosiphum euphorbiae $\left(\chi^{2}=0.098\right.$; d.f. $=1$; n.s. $)$ (Fig. 3).

There was no significant difference between the total number of newly born nymphs on controls and T. longibrachiatum MK1-colonized plants $(t=1.22 ;$ d.f. $=18 ; P=0.24 ; P$ value from 1,000 rounds of permutation $($ Pperm. $)=0.22$ ) (Fig. 4). Conversely, the presence of T. longibrachiatum MK1 on tomato roots seemed to speed up the development of the mirid.

The percentage of first instars relative to the total number of predator nymphs was significantly lower on $T$. longibrachiatum MK1-colonized plants versus uncolonized controls $(t=$ 6.18, df = 18, $P<0.0001$; Pperm. $=0.0001)($ Fig. 5).

\section{DISCUSSION}

One of the most studied beneficial microorganism-plant interactions involves root-colonizing fungi of the genus Trichoderma (Harman et al. 2011; Shoresh et al. 2010). Increasing evidence has been obtained of the beneficial activity of selected Trichoderma strains in terms of induction of systemic resistance against plant pathogens and abiotic stress tolerance (Hanson and Howell 2004; Mastouri et al. 2012) but the influence of these PGPF on plant-insect response has received little attention thus far. A recent paper reported that foliar applications of an endophytic isolate of $T$. viride in combination with Cladosporium cladosporioides significantly reduced the feeding of the specialist beetle Cassida rubiginosa (Coleoptera: Chrysomelidae) but not of the generalist caterpillar Mamestra brassicae (Lepidoptera: Noctuidae) (Gange et al. 2012).

The present article, for the first time, shows that root colonization by a biocontrol strain (MK1) of $T$. longibrachiatum affects the complex web of interactions that determine the development of the aphid pest Macrosiphum euphorbiae and the behavior or development of its natural enemies on tomato plant. The better performance of $M$. euphorbiae in terms of development and reproduction suggests that plants colonized by $T$. longibrachiatum MK1 are not stimulated in terms of resistance mechanisms based on the anti-feedant effect of fungal metabolites (Evidente et al. 2009). In fact, the better performances may be due to a higher nutritional value of the T. lon-

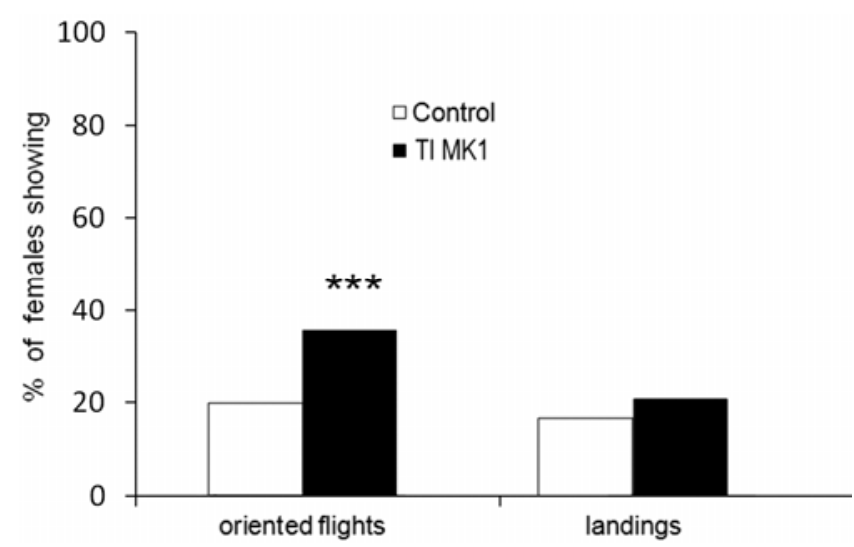

Fig. 1. Behavioral response of Aphidius ervi toward tomato plants uncolonized (control) and colonized by Trichoderma longibrachiatum MK1 (T1 MK1) in wind-tunnel bioassay. Asterisks indicate a significant difference $(P<0.001)$. gibrachiatum MK1-colonized plant with respect to uncolonized controls. Indeed, Trichoderma spp. have been reported to enhance plant absorption of nutrients, especially in poor soils (Altomare and Tringovska 2011; Mastouri et al. 2012; Vinale et al. 2012). In this scenario, aphids could exploit the increased levels of nitrogen and carbon content (Awmack and Leather 2002). This hypothesis is supported by the increased performance of Macrolophus pygmaeus, a zoo-phytophagous predator (Alomar et al. 2002) that retains a phytophagous behavior in the first phases of its life and when there is a scarcity of prey. In these situations, survivorship is granted by feeding on plant juices. The significantly lower proportion of first-instar nymphs recorded 10 days after the oviposition period on aphid-uninfested plants inoculated with T. longibrachiatum MK1 compared with controls indicates that the fungus somehow promotes a faster development of the predator, possibly supported by an increased nutritional value of plant tissues. Aphid development, which was actually favored on T. longibrachiatum MK1-inoculated plants, was instead hampered when roots were colonized by the endomycorrhizal fungus Glomus mosseae (Guerrieri et al. 2004). This contrasting result could be explained considering the difference between the mechanisms of interaction used by the two beneficial microbes: T. longibrachiatum MK1 may have a partially endophytic phase (i.e., hyphae of the fungus invade the first few layers of the root cell) where the fungus remain separate from plant cells

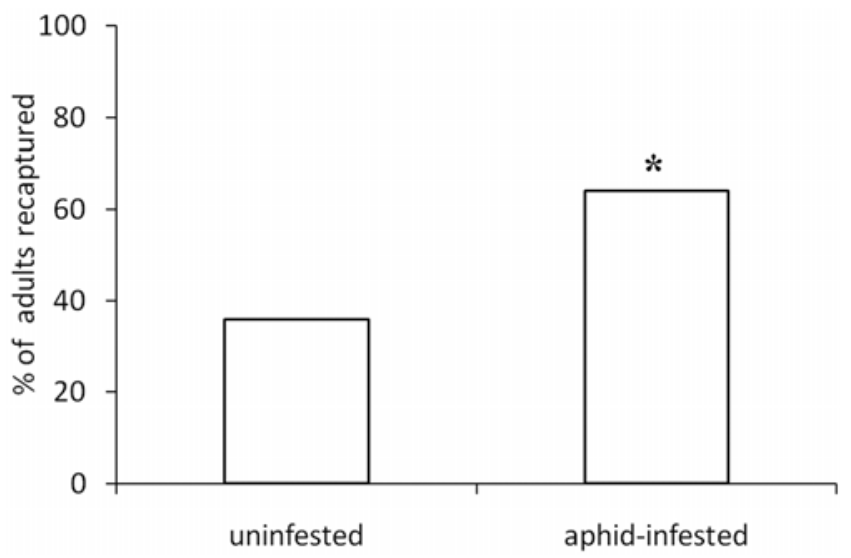

Fig. 2. Percentage of Macrolophus pygmaeus adults recaptured on plants uncolonized by Trichoderma longibrachiatum MK1, with and without aphids, $24 \mathrm{~h}$ after release in choice experiments. Asterisk indicates a significant difference $(P<0.05)$.

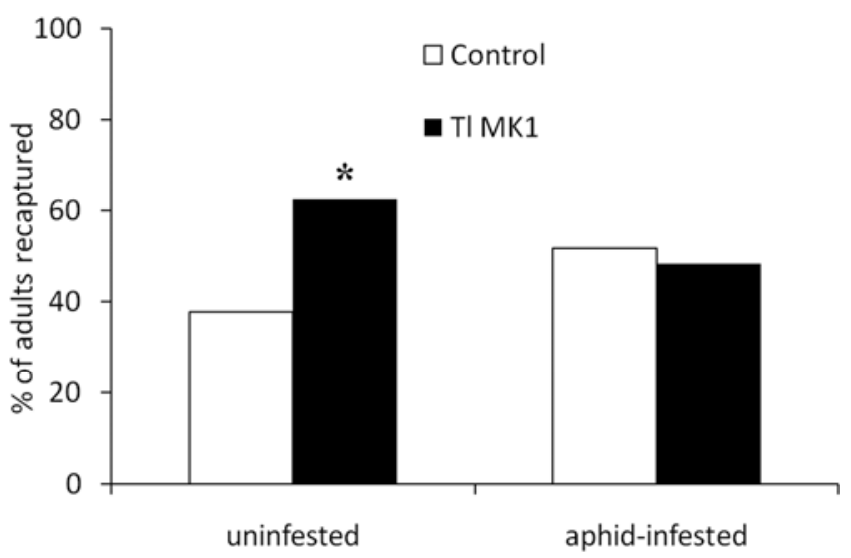

Fig. 3. Percentage of Macrolophus pygmaeus adults recaptured on tomato plants uncolonized (control) and colonized by Trichoderma longibrachiatum MK1 (Tl MK1), $24 \mathrm{~h}$ after release in choice experiments. Asterisk indicates a significant difference $(P<0.05)$. 
(Yedidia et al. 1999), while the colonization of the true symbiont G. mosseae produces, instead, de novo specialized structures (arbuscules and vesicles) in the plant cells (Pozo et al. 2002).

It has been shown that plant pathogens and sap-feeders elicit the salicylic acid defensive pathway, eventually leading to the production of salicylic acid and its volatile methyl ester (Agrawal et al. 1999; Fidansteff et al. 1999; Walling 2000). The relevant increase of methyl salicylate in T. longibrachiatum MK1-colonized plants with respect to controls could have negatively affected aphid performances, as recorded for $G$. mosseae-colonized plants (Digilio et al. 2012; Lòpez-Ràez et al. 2010) (E. Guerrieri, unpublished data). In fact, the positive nutritional effect of $T$. longibrachiatum MK1 on aphid development seemed sufficient to counteract the negative one related to the production of methyl salicylate.

The enhanced release of methyl salicylate, (Z)-3-hexen-1-ol, and $\beta$-caryophyllene by $T$. longibrachiatum MK1-colonized plants can explain the significantly higher attractiveness toward the parasitoid $A$. ervi with respect to control plants. These three compounds have been shown to be important for in-flight orientation of this parasitoid and are recognized at the antennal level at very low concentrations (Sasso et al. 2009). However, the levels of attractiveness showed by $T$. longibrachiatum MK1-colonized plants did not reach those recorded by aphidinfested plants (Sasso et al. 2007). This can be explained by a lower quantity or a different proportion in the release of some (still unknown) attractive volatile compounds.

The attractiveness toward the mirid bug seems to reflect what has been observed for the aphid parasitoid. More specific tests will assess whether the same compounds are attractive toward both natural enemies. For example, $\alpha$-pinene, whose release increases in both aphid-infested and T. longibrachiatum MK1-colonized plants, did not seem to play a role in the attractiveness of $A$. ervi, although we cannot exclude an effect of this monoterpene on M. pygmaeus (Sasso et al. 2007, 2009; Takemoto and Takabajashi 2012). The same considerations apply to longifolene, even though the release of this compound

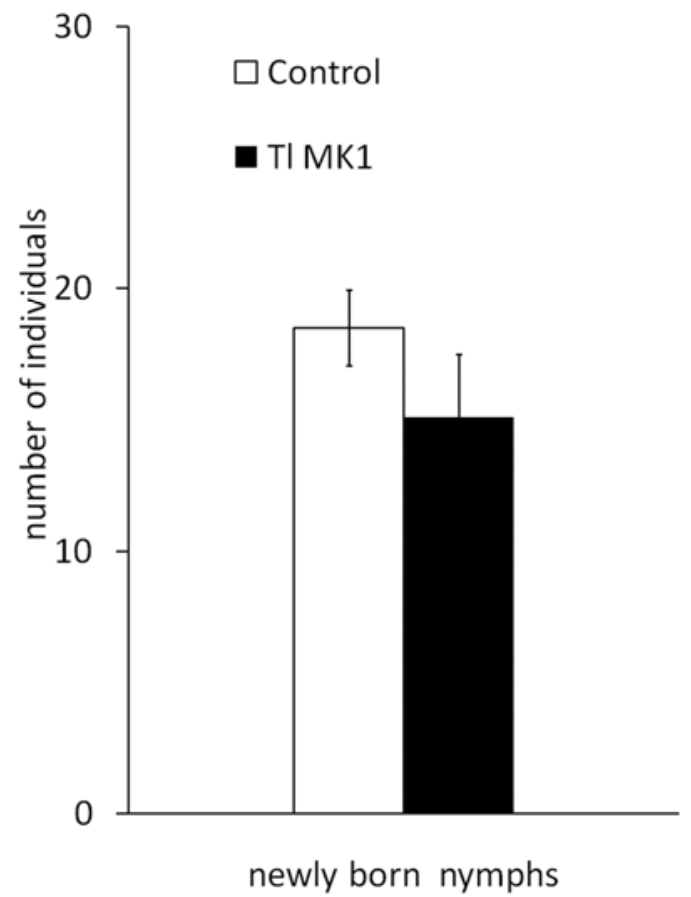

Fig. 4. Number of newly born nymphs of Macrolophus pygmaeus laid on tomato plants uncolonized (control) and colonized by Trichoderma longibrachiatum MK1 (T1 MK1). Bars indicate standard errors. by tomato was not affected by aphid infestation (Sasso et al. 2007, 2009).

The composition of volatiles emitted by T. longibrachiatum MK1-colonized plants suggests the involvement of two signaling pathways. The presence of methyl salicylate indicates the activation of the salicylic acid signaling pathway. This is related to the increased level of disease resistance of plants colonized by T. longibrachiatum MK1 (M. Ruocco, F. Vinale, S. Woo, S. Lanzuise, N. Lombardi, F. Scala, and M. Lorito, unpublished). The presence of terpenes suggests the involvement of the octadecanoid signaling pathway, known to involve jasmonic acid. This pathway has been shown to be activated by the cellulysin from T. viride when the enzyme was applied to leaves of different species including the other solanaceous plant tobacco (Piel et al. 1997).

An interesting question raised from the results of this work is why mycorrhiza, T. longibrachiatum MK1, and aphids elicit a similar defense response in tomato plant in terms of VOC release and indirect defense. Possibly, the "reduced" attractiveness of T. longibrachiatum MK1-colonized plants with respect to aphid-infested and mycorrhizal plants (colonized by $G$. mosseae), due to a different quantity or ratio of induced VOC, can be related at least partially to the "mechanical damage" associated with these organisms. Among the three organisms, T. longibrachiatum MK1 would be the "less" invasive of plant tissues, thus activating a "milder" reaction, whereas aphids and mycorrhiza produce wounds (+ saliva injection) or de novo structures, respectively. A recent work on multitrophic interactions of Arabidopsis showed a very different gene expression profiles for aphid-plant versus microorganism-plant interactions (Bricchi et al. 2012) and the data presented suggest that similar plant responses may emerge from different sets of signaling pathways. Furthermore, increasing evidence is accumulating on the crosstalk between plant primary and secondary metabolism, providing plants with an astonishing plasticity in

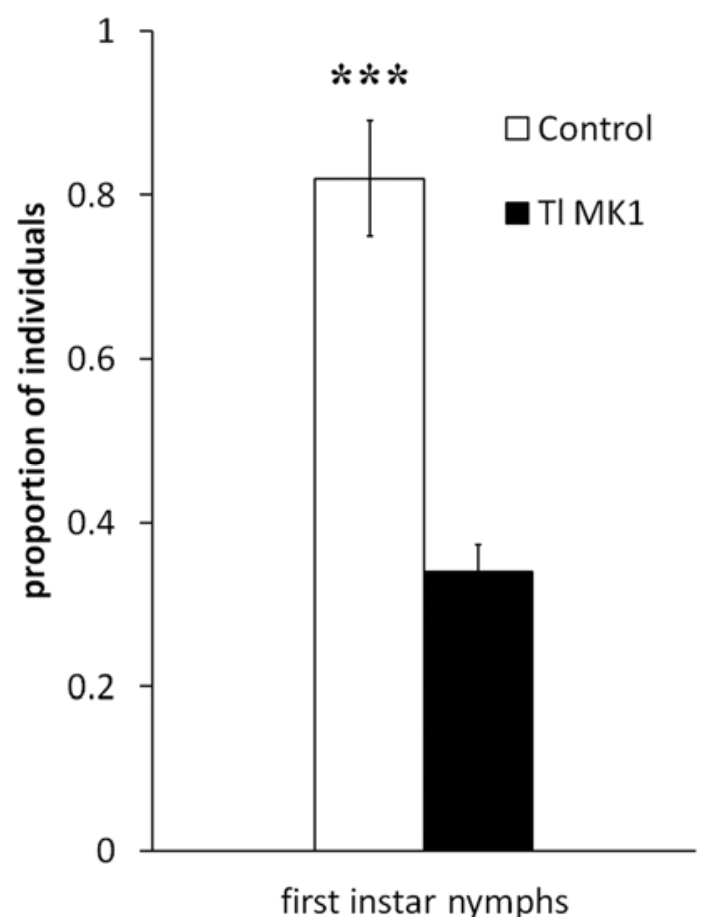

Fig. 5. Proportion of newly born first-instar nymphs on the total number of Macrolophus pygmaeus nymphs recorded on tomato plants uncolonized (control) and colonized by Trichoderma longibrachiatum MK1 (T1 MK1) 10 days after oviposition period. Bars indicate standard errors; asterisks indicate a significant difference $(P<0.001)$ 
terms of growth, development, and defense (Neilson et al. 2013; Robert-Seilaniantz et al. 2011). The stability of the physiological modifications induced by $T$. longibrachiatum MK1 in relation to aphid resistance needs to be assessed. However, Tucci and associates (2011) have shown, for the same PGPF on tomato plants, a beneficial effect on growth promotion and increased resistance against Botrytis cinerea lasting for 2 months (Tucci et al. 2011) (Table 1).

The net effect of root colonization by $T$. longibrachiatum MK1 in terms of plant defense against different insects, also in relation to the changes in plant growth and development, remains to be assessed. In this perspective, Trichoderma fungi may be able to compensate, at least partially, for the energy cost of defense by facilitating the plant uptake of nitrogen and other nutrients, particularly in poor soils (Stamp 2003). Therefore, the improved performances of aphids and their natural enemies on $T$. longibrachiatum-colonized plants may be considered the results of an "increased fitness flow" that starts from the soil microbe and moves up along the food chain to the plant, the aphid, and its predator, a scenario that would be supported by the novel theory of plant response modulated through the interaction between primary and secondary metabolism (Neilson et al. 2013).

The results presented in this article support plant protection strategies developed in a multitrophic contest, and may help to find new methods for defending plants from phytophagous pests. However, two key issues have to be considered: i) in many cases, useful interactions are species specific and even strain specific (Coppetta et al. 2006; Johnson et al. 2012; Kovach-Orr and Fussmann 2013; Soler et al. 2013; Tucci et al. 2011) and ii) the cross-talk between the plant and the entire root-associated microbiome may determine the outcome of many multitrophic interactions, which then need to be investigated more closely to the natural conditions (Bulgarelli et al. 2012; Lundberg et al. 2012).

Sustainable crop protection, as required by new international regulations, will readily benefit from a deeper understanding of the interdependent mechanisms that regulate those below ground-above ground interactions affecting plant resistance to insects and microbial pathogens.

\section{MATERIALS AND METHODS}

\section{Plants and insects.}

The tomato (Solanum lycopersicum L.) genotype selected for this research was the economically important 'San Marzano nano' (= dwarf), sold worldwide canned or as a fresh product. All plants used in the bioassay were 5 weeks old from emergence, permanently reared in a glasshouse at $25 \pm 1^{\circ} \mathrm{C}, 65$ $\pm 5 \%$ relative humidity (RH), and $18 \mathrm{~h}$ of light and $6 \mathrm{~h}$ of darkness before use.

Macrosiphum euphorbiae was reared, since 1998, on tomato 'M82', in an environmental chamber at $20 \pm 1{ }^{\circ} \mathrm{C}, 65 \pm 5 \%$ $\mathrm{RH}$, and a photoperiod of $18 \mathrm{~h}$ of light and $6 \mathrm{~h}$ of darkness, starting from a colony collected on tomato plants, in Scafati (Campania region, Southern Italy). One year before the beginning of lab tests, a colony of $M$. euphorbiae was transferred onto San Marzano nano, known to be highly susceptible to aphid attack (Cornell University database).

The parasitoid wasp $A$. ervi was continuously reared in an environmental chamber at $20 \pm 1^{\circ} \mathrm{C}$, with a photoperiod of 18 $\mathrm{h}$ of light and $6 \mathrm{~h}$ of darkness and $60 \pm 5 \% \mathrm{RH}$, on its natural host, the pea aphid Acyrthosiphon pisum (Harris), maintained on potted broad bean plants (Vicia faba L. 'Aquadulce'), as previously described (Guerrieri et al. 2002).

The predatory bug Macrolophus pygmaeus was supplied by Koppert Italia and reared on potted tomato plants at $25 \pm 5^{\circ} \mathrm{C}$,
$65 \pm 5 \% \mathrm{RH}$, and a photoperiod of $18 \mathrm{~h}$ of light and $6 \mathrm{~h}$ of darkness. Sterilized Ephestia kühniella Zeller (Lepidoptera: Pyralidae) eggs were used as supplemental diet.

\section{Root associated fungus.}

T. longibrachiatum strain MK1 (Moscatiello et al. 2012), isolated from tomato root ('San Marzano') and selected for its rhizosphere competence, plant growth promotion effect, and biocontrol ability, was used in this study. The fungus was grown on potato dextrose agar (PDA) and colonies were allowed to sporulate at $25^{\circ} \mathrm{C}$ in the dark for 7 days. Spores were collected by washing the plates with sterile distilled water and brought to a concentration of $10^{7} \mathrm{ml}^{-1}$. Seed of San Marzano nano were sterilized in $2 \%$ sodium hypochlorite for $20 \mathrm{~min}$ and thoroughly washed in sterile distilled water. Sterilized seed were incubated in a $10^{6} \mathrm{ml}^{-1}$ fresh spore suspension of $T$. longibrachiatum MK1 (coating) or in water (control seed). Coated and control seed were air dried for $24 \mathrm{~h}$, then sown in sterilized soil in a 40 -well polystyrene trays maintained in a growth chamber at $20 \pm 1{ }^{\circ} \mathrm{C}$ and $65 \pm 5 \%$ relative humidity, with a photoperiod of $18 \mathrm{~h}$ of light and $6 \mathrm{~h}$ of darkness. Two weeks after emergence, tomato seedlings were transplanted in 14-cm-diameter plastic pots in sterilized (autoclaved) soil and grown for 3 more weeks in the controlled conditions indicated above.

At the end of each test, roots of five plants for each treatment were analyzed for assessing the presence or absence of the root-colonizing fungus. Eradicated roots were thoroughly washed three times in distilled sterile water and cut into small pieces. Five pieces from each plant root were placed in a petri dish containing PDA with $1 \%$ lactic acid and checked for up to 10 days for the appearance of T. longibrachiatum MK1 colonies.

\section{Effect of T. longibrachiatum MK1 on tomato development and VOC production.}

Plant growth parameters were recorded on $10 \mathrm{~T}$. longibrachiatum MK1-inoculated and 10 control tomato plants by following the procedure reported by Tucci and associates (2011). Values were analyzed by paired $t$ test or Mann-Whitney rank sum test for non-normal distributed data.

Volatiles from 15 aphid-uninfested plants per treatment (control and T. longibrachiatum MK1) were collected for $3 \mathrm{~h}$ by an air-tight entrainment system, using an adsorbent trap made of Tenax TA 60/80 (Sasso et al. 2007), soon after wind tunnel bioassay (see Digilio et al. 2010 for technical details on the system used for collecting and analyzing the volatiles). Volatile compounds were analyzed by gas chromatography coupled to mass spectrometry and identified by comparison of their mass spectra and retention indexes (Kováts indexes) with those of reference substances, where possible, and by comparison with the NIST mass spectral search software v 2.0, using the NIST 98 and Adams libraries (Adams 2001). The mean area of each identified peak and total emission of volatiles were normalized by the weight of the plant, log-transformed to satisfy normality, and analyzed by paired $t$ test (Genstat 11th).

The standards used for the identification of volatiles collected by air-entrainment of head space from tomato plants were chlorobenzene, 6-methyl-5-hepten-2-one, hexanal, (Z)-3hexen-1-ol, $\alpha$-pinene, $\beta$-myrcene, n-decane, (R)-(-)- $\alpha$-phellandrene, $\mathrm{p}$-cymene, $\mathrm{p}$-dichlorobenzene, $\delta$-2-carene, $\alpha$-terpinene, (R)-(+)-limonene, (S)-(-)-limonene, 1,8-cineole, (Z)$\beta$-ocimene, $\gamma$-terpinene, iso-terpinolene, linalool, camphor, menthol, $\alpha$-terpineol, methyl salicylate, eugenol, estragole, $\alpha$ copaene, skatol, $\alpha$-cubebene, (E)-jasmone, (Z)-jasmone, $\alpha$ gurjunene, (+)-longifolene, (E)- $\beta$-caryophyllene, (E)- $\beta$-farnesene, $\alpha$-humulene $(=\alpha$-caryophyllene), and (Z)-nerolidol. 
Effect of T. longibrachiatum MK1 on aphid development and reproduction.

In all, 53 plants for each treatment (control and T. longibrachiatum MK1-inoculated plants) were each infested with a newly born first-instar nymph $(<24 \mathrm{~h}$ old) of Macrosiphum euphorbiae. Assays were carried out at $20 \pm 1{ }^{\circ} \mathrm{C}, 65 \pm 5 \%$ $\mathrm{RH}$, and a photoperiod of $18 \mathrm{~h}$ of light and $6 \mathrm{~h}$ of darkness. Each plant was checked daily to assess the presence of the aphid, the occurrence of molting, and the number of new-laid nymphs.

For each treatment, aphid development and reproduction were evaluated with the procedure suggested by Caughley (1977) by calculating the maximum intrinsic $r_{\mathrm{m}}$ by an iterative solution of the approximation of the Euler equation, $r_{\mathrm{m}}=\log _{\mathrm{e}}$ $\mathrm{R}_{0} / \mathrm{T}$ (Birch 1948), where $\mathrm{R}_{0}=\Sigma l_{\mathrm{x}} m_{\mathrm{x}}$ and $\mathrm{T}=\Sigma \times l_{\mathrm{x}} m_{\mathrm{x}} / \Sigma l_{\mathrm{x}} m_{\mathrm{x}}$, with $l_{\mathrm{x}}$ and $m_{\mathrm{x}}$ representing the age-specific survival and reproductive rate (expressed in days), respectively, assigned by taking the mean development time in days +0.5 as the starting point. The accurate value of $r_{\mathrm{m}}$ was then calculated by solving the equation $\Sigma e^{-\mathrm{rmx}} l_{\mathrm{x}} m_{\mathrm{x}}=1$.

In order to obtain an estimate of the variance and assign confidence intervals to observed differences, we used the bootstrapping procedure described in Meyer and associates (1986), generating 1,000 random recombinations of the original data by sampling with replacement. We then computed the per capita rate of increase for each pseudo matrix so generated and, finally, we computed the mean value and the standard error of the $1,000 \mathrm{r}^{*}$ values. All the bootstrapping resamplings were performed with $\mathrm{R} 2.13 .1$. Longevity and progeny values, as well as $r_{\mathrm{m}}$ values computed by bootstrapping, were compared by two-tailed $t$ test. The numbers of reproducing aphids were compared by a $\chi^{2}$ test in a two-by-two contingency table (Sokal and Rohlf 1995).

\section{Effect of T. longibrachiatum MK1 \\ on tomato attractiveness toward aphid parasitoid.}

For flight behavior bioassays, Aphidius ervi were reared as synchronized cohorts, which were standardized as previously reported (Guerrieri et al. 2002). In brief, broad bean plants heavily infested by Acyrthosiphon pisum were exposed for 24 $\mathrm{h}$ to mated females of the parasitoid. The resulting mummies were isolated and, at their emergence, adult parasitoids were sexed and placed in a box with honey by maintaining a sex ratio of 1:1. Female parasitoids were used for wind tunnel bioassay between 24 and $48 \mathrm{~h}$ after their emergence and had no prior contact with tomato or $M$. euphorbiae (i.e., naive parasitoids).

Relative attractiveness of control and T. longibrachiatum MK1-inoculated plants toward the parasitoid Aphidius ervi was assessed in a wind tunnel bioassay. For each treatment, the attractiveness was measured by testing 15 aphid-uninfested plants over 10 consecutive days. Parameters of the bioassay were set as follows: temperature, $20 \pm 1{ }^{\circ} \mathrm{C}$; RH, $65 \pm 5 \%$; wind speed, $25 \pm 5 \mathrm{~cm} / \mathrm{s}$; distance between releasing vial and

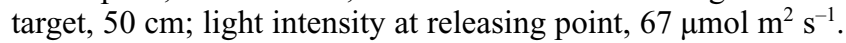
Two hundred parasitoid females were tested singly for each target in single choice experiments and flight behavior data were recorded and analyzed with the aid of event-recording software (The Observer; Noldus Information Technology, Wageningen, The Netherlands).

The percentage of response (oriented flights and landings on the target) to each target was calculated. The number of parasitoids responding to each target in any experiment was compared by a G-test for independence, with William's correction (Sokal and Rohlf 1995). The resulting values of $\mathrm{G}$ were compared with the critical values of $\chi^{2}$ (Sokal and Rohlf 1995).
Effect of T. longibrachiatum MK1

on host plant selection and reproduction of aphid predator.

Host plant selection by $M$. pygmaeus was assessed in a choice bioassay at $25 \pm 1{ }^{\circ} \mathrm{C}, 65 \pm 5 \% \mathrm{RH}$, and a photoperiod of $18 \mathrm{~h}$ of light and $6 \mathrm{~h}$ of darkness. Treatments tested in the bioassay included control plants (no aphids, no Trichoderma), aphid-infested plants (no Trichoderma) - Trichoderma plants (no aphids), and aphid-infested $+T$. longibrachiatum-colonized plant. Aphid-infested plants were obtained by gently transferring 100 mixed-age $M$. euphorbiae onto each tomato plant at least 4 days before the bioassay. Plant attractiveness toward predators was tested by the following combinations of targets: i) $T$. longibrachiatum MK1-colonized plant versus control plant, ii) aphid-infested $+T$. longibrachiatum MK1colonized plant versus aphid-infested plant; and iii) control plant versus aphid-infested plant.

For each combination, plants were placed inside a Plexiglas box ( 70 by 40 by $40 \mathrm{~cm}$ ), $40 \mathrm{~cm}$ away from each other (avoiding any contact between the two plants). Ten adult females of $M$. pygmaeus were released at the center of the cage (at equal distance from each plant). The number of predators on each plant was recorded after $24 \mathrm{~h}$. Ten replications were set up for each experimental combination and the position of the plants inside the box was reversed at each repetition. After assessing the homogeneity of the replicates, we pooled the data and performed a $\chi^{2}$ test in a two-by-two contingency table to compare the frequencies of recaptured adults with the null hypothesis of an equal distribution between the two plants.

The reproduction rate of Macrolophus pygmaeus was assessed on control and $T$. longibrachiatum MK1-colonized plants, individually placed in a plastic box (22 by 15 by $40 \mathrm{~cm}$ ), by releasing 10 adult females and 5 adult males on each plant and allowing an oviposition period (OP) of 4 days. The resulting nymphs were counted 10 days after OP. Ten replicates were set up for this bioassay.

To determine the possible role of the root-associated fungus on the speed of development of the mirid bug, the relative percentage of first-instar nymphs on T. longibrachiatum MK1colonized and control plants was assessed. The data were analyzed by a two-tailed $t$ tests. Probabilities were also verified with a permutation test, each using 10,000 random permutations. Analyses were performed with R 2.13.1.

\section{ACKNOWLEDGMENTS}

This research has been supported bythe Italian Ministry of Education University and Research project n. 5/2010 "Belowground-aboveground interactions: The role of root symbionts in induced defense against aphids in tomato"; European Community FP7 project "Pesticide use-and-risk reduction in European farming systems with Integrated Pest Management (PURE)."

\section{LITERATURE CITED}

Adams, R. P. 2001. Identification of Essential Oil Components by Gas Chromatography/Quadrupole Mass Spectroscopy. Allured Pub. Corporation, Carol Stream, IL, U.S.A.

Agrawal, A. A., Tuzun, S., and Bent, E. 1999. Induced Plant Defenses Against Pathogens and Herbivores: Biochemistry, Ecology, and Agriculture. American Phytopathological Society, St. Paul, MN, U.S.A.

Akpinar, O., Erdogan, K., and Bostanci, S. 2009. Enzymatic production of Xylooligosaccharide from selected agricultural wastes. Food Bioprod. Process. 87:145-151.

Alomar, Ò., Goula, M., and Albajes, R. 2002. Colonisation of tomato fields by predatory mirid bugs (Hemiptera: Heteroptera) in northern Spain. Agric. Ecosyst. Environ. 89:105-115.

Altomare, C., and Tringovska, I. 2011. Beneficial soil microorganisms, an ecological alternative for soil fertility management. Pages 161-214 in: Genetics, Biofuels and Local Farming Systems. E. Lichtfouse, ed. Springer Netherlands, Dordrecht.

Awmack, C. S., and Leather, S. R. 2002. Host plant quality and fecundity in herbivorous insects. Annu. Rev. Entomol. 47:817-844. 
Badri, D. V., De-la-Pena, C., Lei, Z., Manter, D. K., Chaparro, J. M., Guimaraes, R. L., Sumner, L. W., and Vivanco, J. M. 2012. Root secreted metabolites and proteins are involved in the early events of plant-plant recognition prior to competition. PLoS One 7:e46640. Published online.

Bezemer, T. M., and van Dam, N. M. 2005. Linking aboveground and belowground interactions via induced plant defenses. Trends Ecol. Evol. 20:617-624.

Birch, L. 1948. The intrinsic rate of natural increase of an insect population. J. Anim. Ecol.:15-26.

Braun, S. E., Sanderson, J. P., Daughtrey, M. L., and Wraight, S. P. 2012. Attraction and oviposition responses of the fungus gnat Bradysia impatiens to microbes and microbe-inoculated seedlings in laboratory bioassays. Entomol. Exp. Appl. 145:89-101.

Bricchi, I., Bertea, C. M., Occhipinti, A., Paponov, I. A., and Maffei, M. E. 2012. Dynamics of membrane potential variation and gene expression induced by Spodoptera littoralis, Myzus persicae, and Pseudomonas syringae in Arabidopsis. PLoS One 7:e46673-e46673. Published online.

Bulgarelli, D., Rott, M., Schlaeppi, K., Ver Loren van Themaat, E., Ahmadinejad, N., Assenza, F., Rauf, P., Huettel, B., Reinhardt, R., Schmelzer, E., Peplies, J., Gloeckner, F. O., Amann, R., Eickhorst, T., and Schulze-Lefert, P. 2012. Revealing structure and assembly cues for Arabidopsis root-inhabiting bacterial microbiota. Nature 488:91-95.

Caughley, G. 1977. Analysis of Vertebrate Populations. Wiley, New York.

Copetta, A., Lingua, G., and Berta, G. 2006. Effects of three AM fungi on growth, distribution of glandular hairs, and essential oil production in Ocimum basilicum L. var. Genovese. Mycorrhiza 16:485-494.

Digilio, M. C., Corrado, G., Sasso, R., Coppola, V., Iodice, L., Pasquariello, M., Bossi, S., Maffei, M. E., Coppola, M., Pennacchio, F., Rao, R., and Guerrieri, E. 2010. Molecular and chemical mechanisms involved in aphid resistance in cultivated tomato. New Phytol. 187:1089-1101.

Digilio, M. C., Cascone, P., Iodice, L., and Guerrieri, E. 2012. Interactions between tomato volatile organic compounds and aphid behaviour. J. Plant Interact. 7:322-325.

Evidente, A., Andolfi, A., Cimmino, A., Ganassi, S., Altomare, C., Favilla, M., De Cristofaro, A., Vitagliano, S., and Agnese Sabatini, M. 2009. Bisorbicillinoids produced by the fungus Trichoderma citrinoviride affect feeding preference of the aphid Schizaphis graminum. J. Chem. Ecol. 35:533-541.

Fidantsef, A. L., Stout, M. J., Thaler, J. S., Duffey, S. S., and Bostock, R. M. 1999. Signal interactions in pathogen and insect attack: Expression of lipoxygenase, proteinase inhibitor II, and pathogenesis-related protein P4 in the tomato, Lycopersicon esculentum. Physiol. Mol. Plant Pathol. 54:97-114.

Freeman, S., Minz, D., Kolesnik, I., Barbul, O., Zveibil, A., Maymon, M., Nitzani, Y., Kirshner, B., Rav-David, D., and Bilu, A. 2004. Trichoderma biocontrol of Colletotrichum acutatum and Botrytis cinerea and survival in strawberry. Eur. J. Plant Pathol. 110:361-370.

Gange, A. C., Eschen, R., Wearn, J. A., Thawer, A., and Sutton, B. C. 2012. Differential effects of foliar endophytic fungi on insect herbivores attacking a herbaceous plant. Oecologia 168:1023-1031.

Guerrieri, E., and Digilio, M. C. 2008. Aphid-plant interactions: A review. J. Plant Interact. 3:223-232.

Guerrieri, E., Poppy, G. M., Powell, W., Rao, R., and Pennacchio, F. 2002. Plant-to-plant communication mediating in-flight orientation of Aphidius ervi. J. Chem. Ecol. 28:1703-1715.

Guerrieri, E., Lingua, G., Digilio, M. C., Massa, N., and Berta, G. 2004 Do interactions between plant roots and the rhizosphere affect parasitoid behaviour? Ecol. Entomol. 29:753-756.

Hanson, L., and Howell, C. 2004. Elicitors of plant defense responses from biocontrol strains of Trichoderma viren. Phytopathology 94:171176.

Harman, G. E. 2011. Multifunctional fungal plant symbionts: New tools to enhance plant growth and productivity. New Phytol. 189:647-649.

Harman, G. E., Howell, C. R., Viterbo, A., Chet, I., and Lorito, M. 2004. Trichoderma species-opportunistic, avirulent plant symbionts. Nat. Rev. Microbiol. 2:43-56.

Heil, M. 2008. Indirect defence via tritrophic interactions. New Phytol. 178:41-61.

Hermosa, M. R., Keck, E., Chamorro, I., Rubio, B., Sanz, L., Vizcaíno, J. A., Grondona, I., and Monte, E. 2004. Genetic diversity shown in Trichoderma biocontrol isolates. Mycol. Res. 108:897-906.

Hermosa, R., Viterbo, A., Chet, I., and Monte, E. 2012. Plant-beneficial effects of Trichoderma and of its genes. Microbiology 158:17-25.

Hoyos-Carvajal, L., Orduz, S., and Bissett, J. 2009. Genetic and metabolic biodiversity of Trichoderma from Colombia and adjacent neotropic regions. Fungal Genet. Biol. 46:615-631.

Johnson, S. N., Clark, K. E., Hartley, S. E., Jones, T. H., McKenzie, S. W., and Koricheva, J. 2012. Aboveground-belowground herbivore interactions: A meta-analysis. Ecology 93:2208-2215.
Kim, B., Sullivan, R. P., and Zhao, H. 2010. Cloning, characterization, and engineering of fungal L-arabinitol dehydrogenases. Appl. Microbiol. Biotechnol. 87:1407-1414.

Kovach-Orr, C., and Fussmann, G. F. 2013. Evolutionary and plastic rescue in multitrophic model communities. Philos. Trans. R. Soc. B Biol. Sci. 368. Published online.

Krauss, U., and Soberanis, W. 2001. Biocontrol of cocoa pod diseases with mycoparasite mixtures. Biol. Control 22:149-158.

López-Ráez, J. A., Verhage, A., Fernández, I., García, J. M., Azcón-Aguilar, C., Flors, V., and Pozo, M. J. 2010. Hormonal and transcriptional profiles highlight common and differential host responses to arbuscular mycorrhizal fungi and the regulation of the oxylipin pathway. J. Exp. Bot. 61:2589-2601.

Lorito, M., Woo, S. L., Harman, G. E., and Monte, E. 2010. Translational research on Trichoderma: From 'omics to the field. Annu. Rev. Phytopathol. 48:395-417.

Lundberg, D. S., Lebeis, S. L., Paredes, S. H., Yourstone, S., Gehring, J., Malfatti, S., Tremblay, J., Engelbrektson, A., Kunin, V., del Rio, T. G., Edgar, R. C., Eickhorst, T., Ley, R. E., Hugenholtz, P., Tringe, S. G., and Dangl, J. L. 2012. Defining the core Arabidopsis thaliana root microbiome. Nature 488:86-90.

Maffei, M. E., Gertsch, J., and Appendino, G. 2011. Plant volatiles: Production, function and pharmacology. Nat. Prod. Rep. 28:1359-1380.

Markov, A., Gusakov, A., Dzedzyulya, E., Ustinov, B., Antonov, A., Okunev, O., Bekkarevich, A., and Sinitsyn, A. 2006. Properties of hemicellulases of the enzyme complex from Trichoderma longibrachiatum. Appl. Biochem. Microbiol. 42:573-583.

Martinez, C., Blanc, F., Le Claire, E., Besnard, O., Nicole, M., and Baccou, J. C. 2001. Salicylic acid and ethylene pathways are differentially activated in melon cotyledons by active or heat-denatured cellulase from Trichoderma longibrachiatum. Plant Physiol. 127:334-344.

Mastouri, F., Björkman, T., and Harman, G. E. 2012. Trichoderma harzianum enhances antioxidant defense of tomato seedlings and resistance to water deficit. Mol. Plant-Microbe Interact. 25:1264-1271.

Meyer, J. S., Ingersoll, C. G., McDonald, L. L., and Boyce, M. S. 1986. Estimating uncertainty in population growth rates: Jackknife vs. bootstrap techniques. Ecology 67:1156-1166.

Migheli, Q., González-Candelas, L., Dealessi, L., Camponogara, A., and Ramón-Vidal, D. 1998. Transformants of Trichoderma longibrachiatum overexpressing the beta-1,4-endoglucanase gene egl1 show enhanced biocontrol of Pythium ultimum on cucumber. Phytopathology 88:673677.

Moscatiello, R., Sello, S., Ruocco, M., Barbulova, A., Chiurazzi, M., Bonfante, P., Mariani, P., Lorito, M., and Navazio, L. 2012. L'idrofobina Hytral secreta dal fungo di biocontrollo Trichoderma attiva una via di segnalazione mediata dal calcio e geni di difesa in Lotus japonicus. Pages 18-19 in: Gruppi di lavoro "Biologia Cellulare e Molecolare" and "Biotecnologie e differenziamento". Abano TermePadova, Italy.

Neilson, E. H., Goodger, J. Q. D., Woodrow, I. E., and Møller, B. L. 2013. Plant chemical defense: At what cost? Trends Plant Sci. 18:250258.

Piel, J., Atzorn, R., Gäbler, R., Kühnemann, F., and Boland, W. 1997. Cellulysin from the plant parasitic fungus Trichoderma viride elicits volatile biosynthesis in higher plants via the octadecanoid signalling cascade. FEBS (Fed. Eur. Biochem. Soc.) Lett. 416:143-148.

Pineda, A., Zheng, S.-J., van Loon, J. J., Pieterse, C. M., and Dicke, M. 2010. Helping plants to deal with insects: The role of beneficial soilborne microbes. Trends Plant Sci. 15:507-514.

Pozo, M. J., Cordier, C., Dumas-Gaudot, E., Gianinazzi, S., Barea, J. M. and Azcón-Aguilar, C. 2002. Localized versus systemic effect of arbuscular mycorrhizal fungi on defence responses to Phytophthora infection in tomato plants. J. Exp. Bot. 53:525-534.

Rasmann, S., Köllner, T. G., Degenhardt, J., Hiltpold, I., Toepfer, S., Kuhlmann, U., Gershenzon, J., and Turlings, T. C. J. 2005. Recruitment of entomopathogenic nematodes by insect-damaged maize roots. Nature 434:732-737.

Robert-Seilaniantz, A., Grant, M., and Jones, J. D. G. 2011. Hormone crosstalk in plant disease and defense: More than just jasmonate-salicylate antagonism. Annu. Rev. Phytopathol. 49:317-343.

Sánchez, V., Rebolledo, O., Picaso, R. M., Cárdenas, E., Córdova, J., González, O., and Samuels, G. J. 2007. In vitro antagonism of Thielaviopsis paradoxa by Trichoderma longibrachiatum. Mycopathologia 163:49-58.

Sariah, M., Choo, C. W., Zakaria, H., and Norihan, M. S. 2005. Quantification and characterisation of Trichoderma spp. from different ecosystems. Mycopathologia 159:113-117.

Sasso, R., Iodice, L., Digilio, M. C., Carretta, A., Ariati, L., and Guerrieri, E. 2007. Host-locating response by the aphid parasitoid Aphidius ervi to tomato plant volatiles. J. Plant Interact. 2:175-183. 
Sasso, R., Iodice, L., Woodcock, C. M., Pickett, J. A., and Guerrieri, E. 2009. Electrophysiological and behavioural responses of Aphidius ervi (Hymenoptera: Braconidae) to tomato plant volatiles. Chemoecology 19:195-201.

Shoresh, M., Harman, G. E., and Mastouri, F. 2010. Induced systemic resistance and plant responses to fungal biocontrol agents. Annu. Rev. Phytopathol. 48:21-43.

Sokal, R., and Rohlf, F. 1995. Biometry: The Principles and Practice of Statistics in Biological Research. W. H. Freeman \& Co., New York.

Soler, R., Erb, M., and Kaplan, I. 2013. Long distance root-shoot signalling in plant-insect community interactions. Trends Plant Sci. 18:149156

Stamp, N. 2003. Out of the quagmire of plant defense hypotheses. Q. Rev. Biol. 78:23-55.

Takemoto, H., and Takabayashi, J. 2012. Exogenous application of liquid diet, previously fed upon by pea aphids Acyrthosiphon pisum (Harris), to broad bean leaves induces volatiles attractive to the specialist parasitic wasp Aphidius ervi (Haliday). J. Plant Interact. 7:7883.

Tikhonovich, I., and Provorov, N. 2011. Microbiology is the basis of sustainable agriculture: An opinion. Ann. Appl. Biol. 159:155-168.

Tucci, M., Ruocco, M., De Masi, L., De Palma, M., and Lorito, M. 2011. The beneficial effect of Trichoderma spp. on tomato is modulated by the plant genotype. Mol. Plant Pathol. 12:341-354.

Vinale, F., Sivasithamparam, K., Ghisalberti, E. L., Ruocco, M., Wood, S., and Lorito, M. 2012. Trichoderma secondary metabolites that affect plant metabolism. Nat. Prod. Commun. 7:1545.

Walling, L. L. 2000. The myriad plant responses to herbivores. J. Plant Growth Regul. 19:195-216.

Yedidia, I., Benhamou, N., and Chet, I. 1999. Induction of defense responses in cucumber plants (Cucumis sativus L.) by the biocontrol agent Trichoderma harzianum. Appl. Environ. Microbiol. 65:1061-1070.

Yi, H., and Chi, Y. 2011. Biocontrol of Cytospora canker of poplar in north-east China with Trichoderma longibrachiatum. For. Pathol. 41:299-307.

Zhang, C. L., Druzhinina, I. S., Kubicek, C. P., and Xu, T. 2005. Trichoderma biodiversity in China: Evidence for a north to south distribution of species in East Asia. FEMS (Fed. Eur. Microbiol. Soc.) Microbiol. Lett. 251:251-257.

\section{AUTHOR-RECOMMENDED INTERNET RESOURCES}

Cornell University tomato disease-resistance table: vegetablemdonline.ppath.cornell.edu/Tables/TomatoTable.html The R Project for Statistical Computing: www.r-project.org 